\title{
Is job seniority a protective factor against anxiety among midwives during the SARS-CoV-2 pandemic?
}

\author{
Joanna Gotlib ${ }^{1, D-F} \oplus$, Ewa Rzońca ${ }^{1, C-D \oplus}$, Barbara Baranowska ${ }^{2, A-C, E-F} \oplus$, Urszula Tataj-Puzyna ${ }^{2, A-B, E-F \oplus}$, \\ Paulina Pawlicka ${ }^{3, A-C \oplus}$, Mariusz Jaworski ${ }^{1, C, E-F \oplus}{ }^{\text {, Angelina Wójcik-Fatla }}{ }^{4, C, E-F} \oplus$, Mariusz Panczyk ${ }^{1, C, E} \oplus$ \\ ${ }^{1}$ Medical University, Warsaw, Poland \\ 2 Department of Obstetrics, Centre for Postgraduate Medical Education, Warsaw, Poland \\ ${ }^{3}$ Institute of Psychology, University of Gdansk, Poland \\ ${ }^{4}$ Institute of Rural Health, Lublin, Poland \\ A - Research concept and design, B - Collection and/or assembly of data, C - Data analysis and interpretation, \\ $D$ - Writing the article, $E$ - Critical revision of the article, $F$ - Final approval of article
} Gotlib J, Rzońca E, Baranowska B, Tataj-Puzyna U, Pawlicka P, Jaworski M, Wójcik-Fatla A, Panczyk M. Is job seniority a protective factor against
anxiety among midwives during the the SARS-CoV-2 pandemic? Ann Agric Environ Med. 2021; 28(2): 352-357. doi: 10.26444/aaem/136572

\begin{abstract}
Introduction. The pandemic SARS-Cov-2 outbreak necessitated the implementation of changes in everyday obstetric attendance, which demands continuity of care. Employment of sudden changes in obstetric attendance could have increased anxiety among medical personnel.

Objective. The aim of the Communication was to analyse the influence of professional experience on the level of anxiety in a group of midwives during the SARS-CoV-2 pandemic.

Materials and method. The analysis included 100 midwives: average professional experience: 11.51 years (max. 36; median 7,5; SD: 10.37; $p<0.0001)$. The largest group of respondents was employed in a tertiary referral hospital ( $n=40)$, the smallest in a medical clinic $(n=7)$. A preliminary study using an online questionnaire, the Generalized Anxiety Disorder Screener (GAD-7), posted on Internet fora, Facebook fan pages of The Childbirth with Dignity Foundation, and the Foundation for Midwives, using the Snowball sampling method. The Ethics Committee for Research Projects at the Institute of Psychology, University of Gdańsk, approved the research project (Approval No. 35/2020).

Results. The average score was 9.390 (max. 21, median 8.5; SD; 5.228). The length of professional experience did not correspond to the level of anxiety ( $r=-0.0097 ; p=0.9237)$. In 20 respondents, no anxiety was traced, while the smallest group indicated severe anxiety $(n=15)$. Professional experience did not influence the level of anxiety in either group with different level of anxiety (ANOVA test; $p=0.465$ ).

Conclusion. Professional experience did not influence the level of anxiety. In order to prevent exacerbation of anxiety symptoms, different factors which may playa vital role in enhancing the level of anxiety must be analysed.
\end{abstract}

\section{Key words}

anxiety, pandemic, SARS-CoV-2, COVID-19, perinatal care, prenatal care, midwifery, obstetrics

\section{INTRODUCTION}

The pandemic SARS-CoV-2 outbreak (Severe Acute Respiratory Syndrome - Coronavirus 2) has necessitated the rapid implementation of a number of changes in healthcare, including changes in daily perinatal care $[1$ The new recommendations included: the use of personal protective equipment (PPE), attending follow-up appointments at a health centre or postponing follow-up appointments, the use of telemedicine, as well as recommendations on the type of delivery or visits during hospital stays $[2,3,4,5]$. As far as the care for healthy pregnant women in Poland during the SARS-CoV-2 pandemic is concerned, it has been recommended to limit the number of in-person antenatal visits to the minimum, and to adjust the appointment schedule based on each patient's individual health status. This should be carried out by the care provider, i.e. a midwife or a doctor. Although the use of telemedicine has also been

Address for correspondence: Joanna Gotlib, Medical University, Żwirki i Wigury 61, 02-791 Warsaw, Poland

E-mail: joanna.gotlib@wum.edu.pl

Received: 10.03.2021; accepted: 12.05.2021; first published: 31.05 .2021 recommended, in situations requiring an in-person contact with a midwife or doctor, the appointment should take place following all necessary safety precautions, and the pregnant woman should report for her appointment punctually and alone [6-8]. In addition, the Ultrasound Section of the Polish Society of Gynecologists and Obstetricians recommends the use of Covid-19 screening questions prior to ultrasound examinations. The ultrasound examination would only be performed in asymptomatic patients screened as negative, and following safety precautions. Pregnant women screened as positive should be quarantined and the screening ultrasound examination should not be performed. However, in the case of emergencies, hospital care in dedicated COVID health centres is recommended. Moreover, pregnant women with COVID-19 or tested positive for SARS-CoV-2 should have their ultrasound examination performed only in justifiable situations, and in multidisciplinary healthcare facilities dedicated to COVID-19 [6,8,9]. Antenatal education provided by midwives after the 21st week of gestation can only take place with the use of technology. Face-toface antenatal classes must be preceded by COVID-19 screening questions and body temperature measurement. 
During such meetings or classes, it is absolutely essential to follow the guidelines and adhere to all necessary safety precautions for limiting the spread of COVID-19 $[6,8,10]$. The aim of these recommendations was and still is to limit the possibility of infection with the SARS-CoV-2 virus for both patients and the health care professionals who care for them [2-10].

The SARS-CoV-2 virus pandemic has significantly impacted upon the mental health of healthcare professionals who are at the forefront of the fight against it. Research on the impact of the pandemic on the mental health of health care workers has noted an increase in psychological stress, depression and anxiety, demonstrated in systematic reviews and meta-analyses conducted during the current pandemic (Pappa et al., 2020; Luo et al., 2020; Salazar de Pablo et al., Al Maqbali et al., 2020; Allan et al., 2020; da Silva \& Neto, 2020; da Silva \& Neto, 2021) [11-17].

Serrano-Ripoll et al. (2020) identify the determinants predisposing health care workers to depression, severe anxiety, burnout, and post-traumatic stress disorder during a viral epidemic. They indicate that job seniority is one of the important protective factors, whereas an unfavourable work setting may exacerbate the above-mentioned problems [18]. The study by Yu et al. (2020) shows job seniority as one of significant determinants of job satisfaction among first-line health care professionals in the fight against the coronavirus pandemic, in addition to education, length of work in the fight against the epidemic, daily length of sleep, and the type of work performed. Healthcare workers with the longest work experience, i.e. over 12 years, showed greater job satisfaction than those with shorter work experience [19]. Similar results were obtained by Gupta et al. (2020), who state that symptoms of depression and anxiety are more common in respondents with work experience shorter than 10 years [20]. The above-mentioned studies analyzed the role of job seniority in various groups of health care workers during the SARS-CoV-2 pandemic. There is no research focusing specifically on midwives. It is therefore important to investigate this issue with regards to the changes in work setting during the current pandemic.

The implementation of sudden changes in perinatal care in conditions of uncertainty and threats to occupational safety has increased the sense of anxiety among health care workers, including midwives [1-17]. It has also intensified the need to investigate the determinants of these problems [18-20]. This was the basis for undertaking the presented study.

\section{OBJECTIVE}

The aim of the study was to assess the severity of anxiety associated with the SARS-

$\mathrm{CoV}-2$ virus pandemic among midwives. A preliminary analysis was also made of the relationship between the severity of anxiety and job seniority.

\section{MATERIALS AND METHOD}

A total of 100 midwives were included in the study. The average work experience was 11.51 years (min. 2 months; max. 36 years; median 7.5; SD: 10.37). The most numerous group of respondents was employed in tertiary referral hospitals $(\mathrm{n}=40)$; and, respectively, primary and secondary referral hospitals $(n=18)$, community care $(n=16)$, private practice $(n=10)$ or outpatient clinics $(n=7)$. The largest group of study participants was employed in cities with more than 300,000 inhabitants $(n=64)$, and respectively, in cities with fewer than 50,000 inhabitants $(n=15)$, cities with 50,000-150,000 inhabitants $(\mathrm{n}=13)$, cities with 150,000-300,000 inhabitants $(n=9)$, and in the countryside $(n=2)$.

This research was preliminary and conducted from 2-25 April 2020. Data were collected using an online questionnaire. The link to the questionnaire was sent to midwives using the snowball technique. It was also posted on online forums for midwives, on the Facebook page of the Childbirth with Dignity Foundation and the Foundation for the Support of Midwives. The study was conducted using a standardized 7-item screening tool, the Generalized Anxiety Disorder Screener (GAD-7), which measures general anxiety symptoms. The respondents assess the frequency of occurrence of anxiety-related symptoms (0 - not at all, 1 - several days, 2 - more than half the days, 3 - nearly every day). The more points scored, the higher the anxiety level. Obtaining 10 or more points indicated the presence of symptoms of moderate to severe anxiety, whereas obtaining more than 15 points indicated the presence of severe anxiety. Obtaining the maximum number of 21 points indicated a severe anxiety disorder. Analysis of the results of the measurements with GAD-7 allows classification of the respondents into four groups differentiated in terms of the severity of anxiety symptoms (no anxiety, mild anxiety, moderate anxiety, severe anxiety).

The study was approved by the Ethics Committee for Research Projects at the Institute of Psychology, University of Gdańsk (No. 35/2020).

Descriptive statistics methods were used for the analysis of metric variables: mean, standard deviation and coefficient of variation. Non-metric variables were presented using the structure index (frequency and percentage). In order to estimate the relationship between the duration of employment and the severity of anxiety symptoms, the Pearson correlation coefficient was determined. Moreover, in the analysis of potential differences in the average duration of work experience, depending on the group selected according to the severity of anxiety symptoms, $d$ the one-way analysis of variance (ANOVA) was used.

Multivariate analysis was performed to assess the influence of selected independent variables (job seniority, place of work, city of employment, subjective fear of infection) on the severity of anxiety symptoms (dependent variable). A linear regression model was used, taking into account the moderating of the following variables: place of work and city of employment on the level of perceived anxiety. Unstandardized (b) and standardized ( $\beta$ ) regression coefficients with $95 \%$ confidence intervals were calculated. The adjusted R-squared was used to estimate the dependent variable variance (anxiety level).

The sample size was estimated based on the assumed effect size of $\mathrm{f}=0.45$ (large effect). With the alpha level $=0.05$ and the statistical power beta $=0.85$, as well as one covariate and four factor levels, the established count should be 100 . The statistical power was calculated using $G$ * Power version 3.1.9.7 (University of Kiel, Germany).

For all analyzes, the verification of statistical hypotheses was assumed with a default level of statistical significance 
of 0.05 . The calculations were made using the STATISTICA version 33 package (TIBCO Software Inc., Palo Alto, California, USA) under the license of the Medical University of Warsaw.

\section{RESULTS}

In the examined group of midwives, the mean score on the GAD-7 scale was 9.39 (min. 0, max. 21, median 8.50; SD; 5.23) (Tab. 1).

Assessment of the correlation between job seniority and the severity of anxiety symptoms indicated no statistically significant correlation $(\mathrm{r}=-0.01 ; \mathrm{p}=0.924)$. Moreover, it was noted that in the case of 20 study participants, no anxiety was observed (no anxiety, $\mathrm{n}=20$ ); 35 study participants reported mild anxiety (mild anxiety, $\mathrm{n}=35$ ); 30 midwives reported moderate anxiety (moderate anxiety, $n=30$ ), and the smallest group of study participants reported severe anxiety (severe anxiety, $\mathrm{n}=15$ ).

The analysis of variance did not show the mean duration of employment to be statistically significantly different, depending on the group of midwives distinguished on the basis of the severity of depressive symptoms (ANOVA: $\left.\mathrm{F}_{(3,96)}=0.858 ; \mathrm{p}=0.465\right)$. A detailed summary of the study results is presented in Table 2.

Table 1. Summary of results using the GAD-7 scale

\begin{tabular}{lccc}
\hline Statement & Average & SD & CV [\%] \\
\hline Feeling nervous, anxious or on edge & 1.78 & 0.94 & 52.7 \\
\hline Not being able to stop or control worrying & 1.28 & 0.88 & 68.5 \\
\hline Worrying too much about different things & 1.51 & 0.96 & 63.5 \\
\hline Trouble relaxing & 1.50 & 1.00 & 66.7 \\
\hline Being so restless that it's hard to sit still & 0.93 & 0.95 & 101.7 \\
\hline Becoming easily annoyed or irritable & 1.35 & 0.93 & 68.5 \\
\hline Feeling afraid as if something awful might happen & 1.04 & 0.89 & 85.3 \\
\hline Overall Score & 9.39 & 5.23 & 55.7 \\
\hline
\end{tabular}

SD - standard deviation, CV - coefficient of variation

The regression model tested was statistically significant $\left(\mathrm{F}_{(18,81)}=3.545 ; \mathrm{p}<0.001\right.$, standard error of estimation $\left.=1.99\right)$ and explained over $30 \%$ of the dependent variable variance (severity of anxiety symptoms). A direct independent effect on the severity of anxiety symptoms was observed in three out of four dependent variables assessed. Midwives who experienced greater fear due to the possibility of contracting SARS-CoV-2 and developing COVID-19, experienced a greater severity of anxiety symptoms $(\beta=0.43 ; p=0.001)$. On the other hand, midwives working in larger cities (over 300,000 inhabitants) experienced lower severity of anxiety symptoms than those working in towns with less than 300,000 inhabitants $(\beta=-0.25 ; \mathrm{p}=0.046)$. Also, midwives working in outpatient clinics demonstrated a significantly lower severity of anxiety symptoms than those working in primary referral hospitals $(\beta=-1.16 ; \mathrm{p}=0.012)$.

Analysis of the moderating effect of the workplace on the relationship between fear of infection / illness and the severity of anxiety symptoms showed only outpatient clinics to be a significant factor in this regard. The subjective feeling of fear had a much stronger influence on the perceived anxiety in the group midwives working in outpatient clinics than in midwives working in primary referral hospitals $(\beta=1.01$, $\mathrm{p}=0.020$ ). The second significant moderation was observed in the relationship between the city of employment and the severity of anxiety symptoms. The workplace moderator has a diverse influence on this relationship. The study showed a significantly higher severity of anxiety symptoms in midwives employed in large cities (> 300,000 inhabitants) and working in tertiary referral hospitals than among those employed in the same type of healthcare facilities in small towns with less than 300,000 inhabitants $(\beta=0.28 ; p=0.037)$. At the same time, the study showed a significantly lower severity of anxiety symptoms in midwives employed in large cities (> 300,000 inhabitants) and working in private practice than among those employed in the same type of healthcare facilities in small towns with less then 300,000 inhabitants $(\beta=-0.38 ; p=0.035)$. Further details of the regression analysis results are presented in Table 3.

\section{DISCUSSION}

The study showed no correlation between the severity of anxiety and the overall work experience of midwives. The absence of anxiety symptoms was found in the group of midwives with the shortest average length of employment (9 years); midwives with the longest employment experience (14 years) experienced mild anxiety. Nevertheless, it should be noted that in the analyzed group of midwives, the average work experience was about 12 years. Based on the results of the study by Yu et al. (2020) [19], it can be assumed that the analyzed group of midwives had already adapted to the work setting and had realistic expectations regarding their work. It should be noted that the pandemic is a crisis situation and taking into account the work experience of the analyzed group, it can be assumed that this is also the first pandemic experienced by the midwives participating in the study. Therefore, for all midwives it was the first contact with such an epidemic situation and they could have reacted similarly, regardless of the length of work experience. In this context, work experience did not have to be a factor preparing midwives for this situation. This may be confirmed by the results of the study by Gruszczyńska et al. (2014) on the relationship between the length of employment, the level of burnout, and strategies for coping with stress among midwives. In this study, job seniority did not have an impact on the subjective assessment of the psychological burden associated with working as a midwife [21].

Table 2. The level of anxiety and the average duration of work experience

\begin{tabular}{|c|c|c|c|c|c|c|c|c|c|c|}
\hline & \multicolumn{2}{|c|}{ No anxiety $(\mathrm{N}=20)$} & \multicolumn{2}{|c|}{ Mild anxiety $(\mathrm{N}=35)$} & \multicolumn{2}{|c|}{ Moderate anxiety $(\mathrm{n}=30)$} & \multicolumn{2}{|c|}{ Severe anxiety $(\mathrm{N}=15)$} & \multirow{2}{*}{$\mathrm{F} 3,96$} & \multirow{2}{*}{$p^{*}$} \\
\hline & M & SD & M & SD & M & SD & M & SD & & \\
\hline Work experience & 9.65 & 9.44 & 13.63 & 11.79 & 10.20 & 9.74 & 11.70 & 9.28 & 0.858 & 0.465 \\
\hline
\end{tabular}


Table 3. Results of regression analysis to estimate the effect of factors on severity of anxiety symptoms (overall score of GAD-7 scale).

\begin{tabular}{|c|c|c|c|c|c|c|c|}
\hline Factor & Level & b & Beta & $-95 \% \mathrm{Cl}$ & $+95 \% \mathrm{Cl}$ & $\mathrm{t}$ & P-value \\
\hline Intercept & & 3.15 & & & & 1.524 & 0.131 \\
\hline Job seniority & & 0.04 & 0.08 & -0.11 & 0.27 & 0.808 & 0.422 \\
\hline Fear of disease & & 1.06 & 0.43 & 0.19 & 0.68 & 3.571 & 0.001 \\
\hline \multirow[t]{5}{*}{ Place of employment } & Primary referral hospitals (Ref.) & & & & & & \\
\hline & Secondary referral hospitals & 3.49 & 0.40 & -0.24 & 1.04 & 1.253 & 0.214 \\
\hline & Private practice & 4.41 & 0.44 & -0.57 & 1.46 & 0.866 & 0.389 \\
\hline & Community care & 9.83 & 0.94 & -0.09 & 1.98 & 1.812 & 0.074 \\
\hline & Outpatient clinics & -12.33 & -1.16 & -2.06 & -0.26 & -2.558 & 0.012 \\
\hline \multirow[t]{2}{*}{ City of employment } & $<300,000$ inhabitants (Ref.) & & & & & & \\
\hline & $\geq 300,000$ inhabitants & -1.35 & -0.25 & -0.49 & -0.00 & -2.024 & 0.046 \\
\hline & Secondary referral hospitals & -0.93 & -0.10 & -0.37 & 0.17 & -0.714 & 0.477 \\
\hline & Tertiary referral hospitals & 2.35 & 0.28 & 0.02 & 0.54 & 2.126 & 0.037 \\
\hline & Private practice & -3.88 & -0.38 & -0.73 & -0.03 & -2.142 & 0.035 \\
\hline & Community care & 1.28 & 0.12 & -0.16 & 0.40 & 0.850 & 0.398 \\
\hline & Outpatient clinics & -0.17 & -0.02 & -0.29 & 0.26 & -0.111 & 0.912 \\
\hline \multirow[t]{6}{*}{ Place of employment / Fear of disease } & Primary referral hospitals (Ref.) & & & & & & \\
\hline & Secondary referral hospitals & -0.32 & -0.21 & -0.79 & 0.37 & -0.723 & 0.472 \\
\hline & Tertiary referral hospitals & 0.23 & 0.19 & -0.54 & 0.93 & 0.521 & 0.604 \\
\hline & Private practice & -0.57 & -0.34 & -1.35 & 0.67 & -0.675 & 0.502 \\
\hline & Community care & -1.54 & -0.91 & -1.88 & 0.06 & -1.863 & 0.066 \\
\hline & Outpatient clinics & 1.78 & 1.01 & 0.17 & 1.85 & 2.382 & 0.020 \\
\hline
\end{tabular}

Ref. - reference variant; $b$ - unstandardized regression coefficient; $\beta$ - standardized regression coefficient; $\mathrm{Cl}$ - $95 \%$ confidence interval

Yörük \& Güler (2021) conducted a study to identify the relationship between mental resilience, burnout, stress, socio-demographic factors and depression among nurses and midwives during the current pandemic. They showed that about one-third of the surveyed nurses and midwives had symptoms of depression, and the risk of depression was significantly higher in the surveyed midwives than in the nurses. However, they did not find any relationship between depression symptoms and socio-demographic factors [22]. In turn, research on burnout among Swedish midwives conducted by Hildingsson et al. (2013) shows that over a third of the surveyed midwives reported some type of burnout (personal burnout, work burnout, client burnout). Moreover, they showed that burnout was clearly related to the midwives' age along with their work and professional experience - respondents with less than 10 years of work experience reported higher levels of burnout [23].

However, it should be noted that there are scientific reports indicating the existence of a relationship between job seniority and the severity of anxiety or depression in midwives [24]. Båtsman et al. (2020) point to a significant relationship between the occurrence of anxiety symptoms and professional experience - respondents with fewer than 10 years of overall work experience experienced greater severity of anxiety symptoms than midwives with greater work experience [24]. Therefore, it seems justified to take into account other factors related to the work setting that may reduce the severity of anxiety among midwives. Knowledge about the virus, the methods of its transmission and forms of protection may be of key importance; such knowledge can reduce emotional tension, anxiety, and uncertainty. This is particularly important in the context of research clearly showing that the current SARS-CoV-2 virus pandemic has adversely affected the mental health of those health care workers who are in the frontline of fighting COVID-19 by increasing their psychological stress, depression and anxiety [11-17]. Anxiety is of key importance in the context of the pandemic, as it is an emotional state that arises in connection with the imminent danger of infecting oneself or one's relatives with the virus $[25,26]$. Continuous exposure to stress, fear and anxiety not only adversely affects performance in the workplace, but it can also lead to psychiatric disorders [26]. The presented study also demonstrates that midwives experienced varying degrees of anxiety. The results showed that the first, most numerous group among midwives surveyed at the beginning of the SARS-CoV-2 pandemic was the mild anxiety group, with the moderate anxiety group ranking second among the respondents. The obtained data are consistent with other reports, for example, the study by Eftekhar Ardebili et al. (2020 in press) which showed that high levels of stress and anxiety among health workers in Iran were highest in the early stages of the pandemic. Moreover, the participants in the study had feelings of helplessness, hopelessness and despair, and many respondents expressed concerns about the loss of control over the situation, and the fact that their knowledge and skills did not make much difference [27]. Similar observations were made in China where Liu et al. (2020) showed that regardless of whether the surveyed healthcare professionals (especially obstetricians and midwives) had direct contact with COVID-19 patients or not, they reported mild and moderate depression and anxiety more frequently during the 
current pandemic than before its outbreak. They also found that the surveyed obstetricians and midwives who had the necessary and sufficient protective equipment or training, reported depression, anxiety and insomnia less frequently than those who did not [28]. On the other hand, Bender et al. (2020) presented research on the psychological experiences of obstetric patients of maternity wards and health care workers of these wards after the implementation of universal SARS-CoV-2 testing in Philadelphia (USA). In their study, more than half of the surveyed maternity care workers had reported moderate job-related anxiety since the outbreak of the pandemic. Moreover, the introduction of universal SARS$\mathrm{CoV}-2$ testing contributed to an increase in job satisfaction and a reduction in work-related anxiety among the surveyed healthcare workers [29]. On the other hand, Sögüt et al. (2020) conducted research on the relationship between knowledge about COVID-19 and anxiety among Turkish midwifery students during the epidemic. Their research in the second half of March shows that the vast majority (94.4\%) of the surveyed midwifery students had a low level of anxiety [30]. In turn, one-fifth of the surveyed midwives did not feel anxious during the performance of the current study at the beginning of the pandemic in Poland. The study showed that the smallest group of midwives was that with severe anxiety. Furthermore, Bender et al. (2020) also found that the proportion of healthcare professionals surveyed in maternity units, reporting high levels of work-related anxiety increased significantly from $1 \%$ to $27 \%$ during the pandemic [29]. When it comes to counteracting anxiety, it is very important to control the factors that influence the occurrence of anxiety in order to prevent its occurrence in the first place. This means undertaking actions aimed at preventing the occurrence of anxiety [31].

There are solutions that can be implemented, e.g. support for relatives (family and friends), proper nutrition, mental preparation, physical activity, music, psychotherapy, rest, the use of hypnotics or anxiolytics, relaxation training [31]. The study by Apisarnthanarak et al. (2020) showed that most suggestions for improving the emotional well-being of healthcare workers (with regards to fear and anxiety) referred to: continuous and reliable education in the field of infection prevention during a pandemic, better hospital personal protective equipment polic, and mindfulness practices [32]. Moreover, the results of the study by La Torre et al. (2020) suggest that yoga and mindfulness practices effectively reduce stress and anxiety in healthcare workers, providing them with a greater ability to cope with stressful situations [33]. During the first three weeks of the pandemic in the UK, to meet the needs of healthcare professionals, a digital learning package (e-package) was developed with information on strategies for coping with symptoms of anxiety and depression with the help of psychological support, and promoting a healthy lifestyle [34]. The results of the study by Dincer and Inangil (2021) seem interesting as far as anti-anxiety interventions among healthcare professionals are concerned. Their study shows that even a single online Emotional Freedom Techniques group session contributes to the reduction of stress, anxiety and burnout in nurses caring for COVID-19 patients [35].

Limitations. The presented study is not without limitations, and the lack of representativeness in the sample is one of the most important. The psychological variable (anxiety) was analyzed at the beginning of the pandemic, therefore, the change in the severity of anxiety over time could not be assessed. Other important factors that could contribute to the severity of midwives' anxiety were also not taken into account, e.g. their knowledge about the virus, personal protective measures, or participation in specialized training in this field. Despite these limitations, this study provides valuable data on the mental health of midwives during the pandemic and identified implications for psychological intervention.

\section{CONCLUSIONS}

Most midwives experienced anxiety of varying severity associated with the epidemic; this suggests that taking action to reduce the severity of negative emotions among medical staff is crucial. All midwives, regardless of their length of work experience, should undergo psychological counselling.

In the studied group of midwives, job seniority did not affect the level of anxiety; however, the relationship between the two factors may also be affected by other variables that were not included in this study. Therefore, in order to prevent the exacerbation of anxiety symptoms, one should analyze various factors that may play a crucial role in increasing anxiety, e.g. the level of burnout.

Given the pilot design of the study and the small sample size, investigating the level of anxiety among midwives indicates the need for further studies.

\section{REFERENCES}

1. Renfrew MJ, Cheyne H, Craig J, Duff E, Dykes F, Hunter B, Lavender T, Page L, Ross-Davie M, Spiby H, Downe S. Sustaining quality midwifery care in a pandemic and beyond. Midwifery. 2020 Sep; 88: 102759. doi: 10.1016/j.midw.2020.102759. Epub 2020 May 25.

2. Pavlidis P, Eddy K, Phung L, Farrington E, Connolly M, Lopes R, Wilson AN, Homer CSE, Vogel JP. Clinical guidelines for caring for women with COVID-19 during pregnancy, childbirth and the immediate postpartum period. Women Birth. 2020 Nov 3: S1871-5192(20)30372-3. doi: 10.1016/j.wombi.2020.10.015. Online ahead of print.

3. Covid-19 and pregnancy. BMJ 2020; 369: m1672. doi: 10.1136/bmj. m1672 (Published 4 May 2020).

4. Jardine J, Relph S, Magee LA, von Dadelszen P, Morris E, Ross-Davie M, Draycott T, Khalil A. Maternity services in the UK during the coronavirus disease 2019 pandemic: a national survey of modifications to standard care. BJOG 2020; https://doi.org/10.1111/1471-0528.16547

5. Okunade KS, Makwe CC, Akinajo OR, Owie E, Ohazurike EO, Babah OA, Okunowo AA, Omisakin SI, Oluwole AA, Olamijulo JA, Adegbola O, Anorlu RI, Afolabi BB. Good clinical practice advice for the management of pregnant women with suspected or confirmed COVID-19 in Nigeria. Int J Gynaecol Obstet. 2020 Sep; 150(3): 278-284. doi: 10.1002/ijgo.13278. Epub 2020 Jul 9. PMID: 32557562

6. Childbirth with Dignity Foundation, Polish guidelines on care for women during pregnancy, delivery and postpartum period in the SARSCoV-2 pandemic, with reference to the perinatal period, updated in September 2020. https://www.rodzicpoludzku.pl/covid/1461-polskieregulacje-w-zakresie-opieki-nad-kobieta-w-ciazy-porodzie-i-poporodzie-w-czasie-pandemii-sars-cov-2-dotyczy-kobiet-w-okresie-okoloporodowym-5.html (access: 2021.04.09)

7. Zimmer M. Recommendations on caring for pregnant women with Covid-19. https://www.ptgin.pl/rekomendowana-sciezkapostepowania-dla-kobiet-w-ciazy-covid-19 (access: 2021.04.09).

8. Węgrzynowska M, Doroszewska A, Witkiewicz M, Baranowska B. Polish maternity services in times of crisis: in search of quality care for pregnant women and their babies, Health Care for Women International. 2020; 41: 11-12: 1335-1348. doi: 10.1080/07399332.2020.1830096

9. Zimmer M, Borowski D. Guidelines of the Ultrasound Section of the Polish Society of Gynecologists and Obstetricians on ultrasound 
examinations in the COVID-19 pandemic. https://www.ptgin.pl/ zalecenie-sekcji-ultrasonografii-ptgip-w-zakresie-badan-usg-wsytuacji-epidemiologicznej-covid-19 (access: 2021.04.09).

10. Polish Ministry of Health: National Consultant in Obstetrics and Gynaecology: Update of Polish recommendations and guidelines for family midwives/primary care midwives during SARS-CoV-2 and COVID-19 pandemic. https://www.gov.pl/web/zdrowie/aktualizacjazalecen-w-stanie-epidemii-wirusa-sarscov2-dla-poloznychrodzinnych-poz (access: 2021.04.09).

11. Pappa S, Ntella V, Giannakas T, Giannakoulis VG, Papoutsi E, Katsaounou P. Prevalence of depression, anxiety, and insomnia among healthcare workers during the COVID-19 pandemic: a systematic review and meta-analysis. Brain Behav Immun. 2020; 88: 901-7.

12. Luo M, Guo L, Yu M, Jiang W, Wang H. The psychological and mental impact of coronavirus disease 2019 (COVID-19) on medical staff and general public - A systematic review and meta-analysis. Psychiatry Res. 2020 Sep; 291: 113190. doi: 10.1016/j.psychres.2020.113190. Epub 2020 Jun 7.

13. da Silva FCT, Neto MLR. Psychiatric symptomatology associated with depression, anxiety, distress, and insomnia in health professionals working in patients affected by COVID-19: A systematic review with meta-analysis. Prog Neuropsychopharmacol Biol Psychiatry. 2021 Jan 10; 104: 110057. doi: 10.1016/j.pnpbp.2020.110057. Epub 2020 Aug 7.

14. Salazar de Pablo G, Vaquerizo-Serrano J, Catalan A, Arango C, Moreno C, Ferre F, Shin JI, Sullivan S, Brondino N, Solmi M, Fusar-Poli P. Impact of coronavirus syndromes on physical and mental health of health care workers: Systematic review and meta-analysis. J Affect Disord. 2020 Oct 1; 275: 48-57. doi: 10.1016/j.jad.2020.06.022. Epub 2020 Jun 25.

15. AlMaqbali M, AlSinani M, Al-LenjawiB. Prevalence of stress, depression, anxiety and sleep disturbance among nurses during the COVID-19 pandemic: A systematic review and meta-analysis. J Psychosom Res. 2020 Dec 17; 141: 110343. doi: 10.1016/j.jpsychores.2020.110343. Online ahead of print.

16. Allan SM, Bealey R, Birch J, Cushing T, Parke S, Sergi G, Bloomfield $\mathrm{M}$, Meiser-Stedman R. The prevalence of common and stressrelated mental health disorders in healthcare workers based in pandemic-affected hospitals: a rapid systematic review and metaanalysis. Eur J Psychotraumatol. 2020 Oct 16; 11(1): 1810903. doi: 10.1080/20008198.2020.1810903

17. da Silva FCT, Neto MLR. Psychological effects caused by the COVID-19 pandemic in health professionals: A systematic review with metaanalysis. Prog Neuropsychopharmacol Biol Psychiatry. 2021 Jan 10; 104: 110062. doi: 10.1016/j.pnpbp.2020.110062. Epub 2020 Aug 6.

18. Serrano-Ripoll MJ, Meneses-Echavez JF, Ricci-Cabello I, FraileNavarro D, Fiol-deRoque MA, Pastor-Moreno G, Castro A, RuizPérez I, Zamanillo Campos R, Gonçalves-Bradley DC. Impact of viral epidemic outbreaks on mental health of healthcare workers: a rapid systematic review and meta-analysis. J Affect Disord. 2020 Dec 1; 277: 347-357. doi: 10.1016/j.jad.2020.08.034. Epub 2020 Aug 23.

19. Yu X, Zhao Y, Li Y, Hu C, Xu H, Zhao X and Huang J. Factors Associated With Job Satisfaction of Frontline Medical Staff Fighting Against COVID-19: A Cross-Sectional Study in China. Front. Public Health 2020; 8: 426. doi: 10.3389/fpubh.2020.00426

20. Gupta S, et al. Survey of prevalence of anxiety and depressive symptoms among 1124 healthcare workers during the coronavirus disease 2019 pandemic across India, Medical Journal Armed Forces India, https:// doi.org/10.1016/ j.mjafi.2020.07.006

21. Gruszczyńska M, Skowrońska E, Bator A, Bąk-Sosnowska M. Staż pracy, poziom wypalenia zawodowego i strategie radzenia sobie ze stresem wśród położnych. Med Og Nauk Zdr. 2014; 20(3): 276-281. doi: $10.5604 / 20834543.1124657$

22. Yörük S, Güler D. The relationship between psychological resilience, burnout, stress, and sociodemographic factors with depression in nurses and midwives during the COVID-19 pandemic: A crosssectional study in Turkey. Perspect Psychiatr Care. 2021 Jan; 57(1): 390-398. doi: 10.1111/ppc.12659. Epub 2020 Oct 26.

23. Hildingsson I, Westlund K, Wiklund I. Burnout in Swedish midwives. Sex Reprod Healthc. 2013 Oct; 4(3): 87-91. doi: 10.1016/j. srhc.2013.07.001. Epub 2013 Jul 30.

24. Båtsman A, Fahlbeck H, Hildingsson I. Depression, anxiety and stress in Swedish midwives: A cross-sectional survey. Eur J Midwifery. 2020 Jul 27; 4: 29. doi: 10.18332/ejm/124941. eCollection 2020.

25. Aksoy YE, Koçak V. Psychological effects of nurses and midwives due to COVID-19 outbreak: The case of Turkey. Arch Psychiatr Nurs. 2020 Oct; 34(5): 427-433. doi: 10.1016/j.apnu.2020.07.011. Epub 2020 Jul 8. PMID: 33032769

26. Salari N, Khazaie H, Hosseinian-Far A, Khaledi-Paveh B, Kazeminia M, Mohammadi M, Shohaimi S, Daneshkhah A, Eskandari S. The prevalence of stress, anxiety and depression within front-line healthcare workers caring for COVID-19 patients: a systematic review and metaregression. Hum Resour Health. 2020 Dec 17; 18(1): 100. doi: 10.1186/ s12960-020-00544-1

27. Eftekhar Ardebili M, Naserbakht M, Bernstein C, AlazmaniNoodeh F, Hakimi H, Ranjbar H. Healthcare providers experience of working during the COVID-19 pandemic: A qualitative study. Am J Infect Control. 2020 Oct 6; S0196-6553(20)30896-8. doi: 10.1016/j. ajic.2020.10.001. Online ahead of print.

28. Liu T, Zheng Z, Sha X, Liu H, Zheng W, Su H, Xu G, Su KP, So KF, Lin K. Psychological impact in non-infectious disease specialists who had direct contact with patients with COVID-19. BJPsych Open. 2020 Dec 7;7(1):e8. doi: 10.1192/bjo.2020.147

29. Bender WR, Srinivas S, Coutifaris P, Acker A, Hirshberg A. The Psychological Experience of Obstetric Patients and Health Care Workers after Implementation of Universal SARS-CoV-2 Testing. Am J Perinatol. 2020 Oct; 37(12): 1271-1279. doi: 10.1055/s-0040-1715505. Epub 2020 Aug 5.

30. Sögüt S, Dolu İ, Cangöl E. The relationship between COVID-19 knowledge levels and anxiety states of midwifery students during the outbreak: A cross-sectional web-based survey. Perspect Psychiatr Care. 2021 Jan; 57(1): 246-252. doi: 10.1111/ppc.12555. Epub 2020 Jun 14.

31. Salari N, Khazaie H, Hosseinian-Far A, Khaledi-Paveh B, Kazeminia M, Mohammadi M, Shohaimi S, Daneshkhah A, Eskandari S. The prevalence of stress, anxiety and depression within front-line healthcare workers caring for COVID-19 patients: a systematic review and metaregression. Hum Resour Health. 2020; 17; 18(1): 100. doi: 10.1186/ s12960-020-00544-1

32. Apisarnthanarak A, Apisarnthanarak P, Siripraparat C, Saengaram P, Leeprechanon N, Weber DJ. Impact of anxiety and fear for COVID-19 toward infection control practices among Thai healthcare workers. Infect Control Hosp Epidemiol. 2020 Sep; 41(9): 1093-1094. doi: 10.1017/ ice.2020.280. Epub 2020 Jun 8.

33. La Torre G, Raffone A, Peruzzo M, Calabrese L, Cocchiara RA, D'Egidio V, Leggieri PF, Dorelli B, Zaffina S, Mannocci A, Yomin Collaborative Group. Yoga and Mindfulness as a Tool for Influencing Affectivity, Anxiety, Mental Health, and Stress among Healthcare Workers: Results of a Single-Arm Clinical Trial. J Clin Med. 2020 Apr 7;9(4): 1037. doi: $10.3390 /$ jcm 9041037

34. Blake H, Bermingham F, Johnson G, Tabner A. Mitigating the psychological impact of COVID-19 on healthcare workers: a digital learning package. Int J Environ Res Public Health. 2020; 17(9): 2997. https://doi.org/10.3390/ijerph17092997

35. Dincer B, Inangil D. The effect of Emotional Freedom Techniques on nurses' stress, anxiety, and burnout levels during the COVID-19 pandemic: A randomized controlled trial. Explore (NY). $2021 \mathrm{Mar}-\mathrm{Apr}$; 17(2): 109-114. doi: 10.1016/j.explore.2020.11.012. Epub 2020 Dec 3. 